\title{
Validity, Lasting Outcomes and Fairness of Learner Assessment from the Perspective of Educational Neuroscience
}

\author{
Chandana Watagodakumbura, ${ }^{1, *}$ \\ ${ }^{1}$ School of Engineering and Technology, Central Queensland University, Melbourne, Australia \\ *Correspondence: School of Engineering and Technology, Central Queensland University, \\ 120, Spencer St, Melbourne, VIC, 3000, Australia. Tel: 61-3-9616-0555 E-mail: \\ c.watagodakumbura@cqu.edu.au
}

Received: February 23, 2017 Accepted: March 13, 2017 Published: March 16, 2017

doi:10.5296/ije.v9i1.10806 URL: https://doi.org/10.5296/ije.v9i1.10806

\begin{abstract}
When setting up assessments, additional viewpoints that need to be considered by viewing from the standpoint of educational neuroscience are discussed in this article. Learner assessment performed in any teaching-learning environment should produce valid and lasting outcomes. The validity of assessment indicates that the results generated represent the learner characteristics reliably using any strengths and weaknesses. The lasting feature of assessment entails that the results are associated with learner characteristics rather the environmental factors. When learner characteristics are identified in this manner, appropriate measures can be taken to improve on any weaknesses identified while at the same time relying or staying motivated on the strengths. It is imperative that educators make use of the findings from the emerging field of educational neuroscience to design and construct assessment producing valid and lasting outcomes. In educational neuroscience, how the human brain and related structures engage in learning processes is studied. By incorporating this useful information into teaching-learning processes, learners can be put on a path to creating useful, lasting memories, across disciplinary boundaries, to lead them to higher levels of human development yielding wisdom and consciousness. When assessments produce valid and lasting outcomes, they essentially become fair for all types of learners including the gifted learners who demonstrate right cerebral hemisphere oriented visual-spatial characteristics that include higher sensitivities such as emotional sensitivity.
\end{abstract}

Keywords: educational neuroscience. learner assessment, the validity of assessment, fairness of assessment, lasting value of assessment, higher-order learning, transfer of learning 


\section{Introduction}

When formulating learner assessment in any teaching-learning environment, validity, lasting outcomes and fairness are important considerations. To address these parameters, we necessarily should take enlightening research findings from the field of educational neuroscience into account. In learning processes, which will last a lifetime, we engage in a task of developing our brains or creating useful neural networks of knowledge that lead to enhanced levels of wisdom and consciousness, or human development overall. Generating valid, fair and lasting assessment outcomes will guide individuals in their lifelong journey of learning through an understanding of one's strengths and weaknesses. The focus of assessment should not always be on the ranking of learners in a very narrow sense as we commonly find in many teaching-learning environments. The purpose of this article is to raise awareness on developing valid and fair assessments that produce lasting outcomes by incorporating the additional valuable perspective of educational neuroscience. The paper is organised mainly into three sections. The first section introduces some essential neuroscience-based facts to readers so that they will be better equipped for following the subsequent sections. Some important learning related concepts are discussed from the viewpoint of neuroscience in section two. In the third and last part, we apply the neuroscience-based concepts discussed in the two previous sections to the tasks of constructing valid and fair assessments yielding lasting outcomes.

\section{Introduction to Primarily Neuroscience-Based Concepts that Relate to Learning}

\subsection{Basic Structure of the Human Brain}

Mainly there are three layers of the brain, from bottom to top: the reptilian brain, mammalian brain and neocortex (Baars and Gage, 2010; MacLean, 1967). The reptilian brain is the oldest layer of the brain; it is composed of the brain stem, the structures that dominate in the brains of snakes and lizards. This part of the brain controls survival activities such as breathing, heart rate and balance. The mammalian brain is layered over the reptilian brain, and consists of a system of brain parts called the limbic system. The constituents of the limbic system include the amygdala, hippocampus and hypothalamus. The limbic system plays a significant role in human emotions. The third layer of the brain is the neocortex or primate brain, which is the most recent addition to our brain. It consists of the wrinkled covering of cerebral hemispheres - the left and right. The neocortex plays a major role in cognitive, linguistic, motor, sensory and social abilities. It gives considerable flexibility in creativity in adapting to changing environments. The neocortex is densely interconnected with the limbic system and controls the expression of emotions.

The neocortex has four major lobes, namely, the frontal lobe, parietal lobe, temporal lobe and occipital lobe. One significant feature of the brain structure is brain localisation. That is, the brain is composed of many functionally specialised regions (Luria, 1976; Geschwind, 1979; Edelman and Mountcastle, 1978). There are about 100 Brodmann areas, so to speak, now recognised in the neocortex. The four lobes of the neocortex and their processes are 
intricately intertwined with each other. Further, the neocortex, which is vital for cognitive functions, interacts constantly with major so-called satellite organs such as the thalamus, basal ganglia, cerebellum, hippocampus and limbic regions.

It is of particular interest to know that frontal lobes are referred to as the organ of civilisation. The role the frontal lobes play in cognition is uniquely human and without their development civilisation could never have arisen (Fuster, 1997; Goldberg, 2001; Ingvar, 1985; Luria, 1966). They are crucial for all higher-order purposeful behaviours such as identifying the objective, projecting the goal, forging plans to reach it, organising how such plans can be carried out and monitoring and judging the consequences. Further, frontal parts of the brain become active when resolving conflicting conditions. A correlation has also been identified between frontal activation and longer reaction time and sense of subjective effort. In summary, the frontal lobe, or more specifically the pre-frontal cortex (PFC), is used for human activities such as language, thought and executive control of higher-order processes and connect directly with every distinct functional unit of the brain (Nauta, 1972). This connectivity allows PFC to coordinate and integrate the functions of other brain structures.

\subsection{Brain Lateralisation}

The ability of certain areas of the brain to perform unique functions is known as cerebral specialisation. If the activity is mainly limited to one hemisphere, it is called cerebral lateralisation. Research studies show that the right and left hemispheres of the brain have distinctly different functions that are not readily interchangeable (Sperry, 1966). The left hemisphere processes input in sequential and analytical manner, is time sensitive, generate the spoken language, does arithmetic operations, recognise words and numbers (as words), active in constructing false memories, better at arousing attention to deal with outside stimuli. The right hemisphere processes inputs more holistically and abstractly, is space sensitive, interprets language through gestures, facial movements, emotions, and body language, does relational and mathematical operations, recognises faces, places, objects and music, more truthful in recall, put events in spatial patterns, better in internal processing, gathers information more from images than from words and look for visual patterns (Gazzaniga 1998a, 1998b; Gazzaniga, Ivry \& Mangun, 2002; Semenza et al., 2006; Sweeney, 2009).

Further, the left and right hemispheres are found to be physically different. The left hemisphere has more grey matter, while the right hemisphere has more white. That is, the left hemisphere's more tightly packed neurones are better able to handle intensely detailed work, while the right hemisphere's white matter contains neurones with longer axons that can connect with modules farther away. These long-range connections help the right hemisphere to come up with broad but rather vague concepts, explaining the association with creativity. However, one of the interesting features of the human brain is that it can integrate different activities taking place in specialised areas into a unifying whole. In fact, the two cerebral hemispheres are connected by the largest fibre bundle in the brain known as the corpus callosum.

Despite this significant revelation, it is widely observed and accepted that educational institutes are predominantly left-hemispheric oriented with emphasis on structured 
environments that run to specific time schedules, favouring facts and rules over patterns and mainly following verbal instructions.

\subsection{Types of Memory}

Human memory (Squire, 2004, 2009; Baars and Gage, 2010) can be defined as a lasting representation that is reflected in thought, experience, and behaviour. It can be divided into two main types: explicit and implicit. Explicit memory refers to the memory with conscious awareness, and the individual can declare its existence and comment on its content either verbally or non-verbally (Cohen \& Squire, 1980; Ryle, 1949). Consequently, such memories are known as declarative memories. On the other hand, implicit memory is not accompanied by the conscious awareness that one has a memory; the existence of implicit memory is inferred only from the effects it has on behaviour. Further, implicit memories may be retained without an intention to remember and accessed commonly by priming tasks (Banaji \& Greenwald, 1995; Curran, 2001; Knowlton et al., 1996).

Explicit or declarative memory can be further divided into two types: episodic (autobiographical) memory and semantic memory (Tulving, 1972; 1985). Episodic memory refers to memories that have a particular source in time, space and life circumstances. In contrast, semantic memories involve facts (or high-level concepts and generalisations) about us, the world, and other knowledge that we share within a community and are independent of the spatial and temporal context in which they were acquired. Further, episodic memories are remembered consciously and susceptible to forgetting while semantic memories give a feeling of knowing rather than a fully conscious recollection and less vulnerable to forgetting. Initially, memories are episodic and context dependent, and over time they are transformed into semantic memories (Penfield and Milner, 1958).

Another categorisation of human memory is the division into the two types referred to as working memory (Baddeley, 2000; Baddeley and Hitch, 1974; Cowan et al., 2005) and long-term memory (Dudai, 2004; LeDoux, 1996; Lees et al., 2000; McGaugh, 2000). Working memory is defined as the set of mental processes holding limited information in a temporarily accessible state in service of cognition. The prefrontal cortex (PFC) seems to play a major role in working memory processes, and temporal and prefrontal regions of the cortex appear to involve in working storage. Long-term memory, on the other hand, can be large quantities of information stored on a more permanent or longer duration basis. The neocortex is believed to encode long-term memories by altering synaptic connections between billions of neurones. There are trillions of such synapses in the cortex and its satellite organs. Memories are believed to be unstable and vulnerable to interference in the early hours after they are formed, and after about a day, they appear to be consolidated or made more enduring (Hobson and Stickgold, 1995). This process of consolidation is thought to require protein synthesis and sleep and dreaming seem to support this process.

\subsection{Types of Learning}

Learning can be defined as the acquisition of lasting representations that involve a broad range of brain areas and activities (Baars and Gage, 2010). Very often, the unstated goal of 
learning is to turn explicit problem solving into the implicit kind. Like we discussed explicit and implicit memories, learning can also be explicit or implicit. Explicit or declarative learning involves conscious learning while implicit (unconscious) learning (Berry and Dienes, 1993; Cleeremans, 1993) results as a side effect of conscious input. That is, even for implicit learning, conscious events guide the learning process. But there is no exclusively conscious learning as both, conscious and unconscious processes always go together. In a complete learning cycle, three phases can be identified: learning, retention and retrieval. Retention is generally viewed as unconscious, although it is shaped by conscious experiences. Explicit learning generally occurs when we pay attention to new information so that it becomes conscious. The brain begins learning as soon as it is placed in any novel environment. Simple novelty is enough to trigger attention and learning, including significantly evoked potentials that sweep through the entire cortex. As soon as we experience or understand the new information with enough clarity, our brains can store it (Seitz \& Watanabe, 2005). Sometimes it may require repeated attention to new or challenging information for us to get a sense of clarity. Any new material may seem vague or hard to understand at first; however, when we spend time thinking about it or paying attention to it, a clearer sense of meaning tends to appear.

The most of our learning is identified to be incidental (Eide \& Eide, 2004), meaning that it occurs because of paying attention and becoming conscious. That is, we do not deliberately memorise things all the time; memorising is only one way to make learning happen.

With our current practices, academic learning is mostly explicit with teachers pointing out the things to be learned and students doing their best to memorise them. However, most ordinary human learning is implicit (Bowers et al., 1990; James, 1890; Metcalfe, 1986; Yzerbyt et al., 1998). For example, social habits and language are mostly learnt implicitly. Looking from another perspective, the most of our knowledge is tacit knowledge, and the most of our learning takes place implicitly before it can be stated explicitly. Further, academic exams usually test associative recall (What is the capital of Australia?) rather than recognition tests. Associative recall tests give much lower estimates for accurate memories than recognition tests. That is, in the associative recall, we expect more exact and precise answers than in recognition tests. Interestingly, these exact and precise answers are the ones that are likely to be forgotten soon (Tulving, 1972; 1985).

In the event of some emotional stimuli, there is evidence that unconscious learning takes place. That is, this gives much stronger evidence for implicit learning, in which some inferential process takes conscious input and encodes unconscious results. In other words, emotional learning results in implicit emotional memory that retains classically conditioned emotional relationships that cannot be voluntarily recollected or reported (Phelps and LeDoux, 2005; Panksepp, 1998). Psychological evidence shows that moderate levels of emotional arousal at the time of an event lead to better retention of explicit memories (Sylwester, 1998). That is, explicit memories are better consolidated by the reception of emotional stimuli by the amygdala. 


\subsection{Consciousness}

Scientists have confirmed that consciousness can be defined and studied scientifically, contrary to the beliefs held otherwise, previously (Baars et al, 2003; Baars and Gage, 2010 Edelman, 1989, 1993, 2005, 2007; Edelman \& Tononi, 2001; Koch, 1996; Palmer, 1999; Tononi \& Edelman, 1998; Tulving, 2002). Consciousness results from the neuronal interaction between thalamocortical systems; the neocortex is the primary organ involved in it. The evolution of consciousness is understood to be the highest expression of the developed brain that parallels the evolution of the prefrontal cortex (PFC). Synonyms used for consciousness are awareness, explicit cognition and focal attention. Consciousness can be identified mainly in two levels - primary and higher-order consciousness. The former is concerned with the perceptual world while the latter is related to abstractions and thought. Further consciousness involves a range of contents: sensory perception, visual imagery, emotional feelings, inner speech, abstract concepts and action related ideas indicating the involvement of a number of brain regions, through an integrative view.

Of particular interest to the phenomenon of consciousness is the theory developed by Giulio Tononi in the name of The Integrated Theory of Consciousness (Balduzzi \& Tononi, 2008; Koch and Tononi, 2008; Tononi, 2008). It provides a new way to study consciousness using a rigorous scientific approach. The integrated theory of consciousness is a framework that is built on the notion that consciousness is a consequence of systems that have both a large amount of differentiated information that is also highly integrated. To summarise the idea, a computer may have a large quantity of memory (say $16 \mathrm{~GB}$ ), but since these memory pieces are not integrated, computers do not have consciousness. Scientists have also been able to quantify the level of consciousness with a measure called neural complexity (C) (Edelman \& Tononi, 2001). High values of $\mathrm{C}$ characterise conscious events and reflects the extent to which the dynamics of a neural system are both integrated and differentiated.

\subsection{Automaticity}

In general, the more predictable a sensorimotor skill becomes, the less of it will become conscious. The fading of conscious access to habitual skills is commonly called 'automaticity' and it goes along with a loss of precise voluntary control over habitual details (Baars and Gage, 2010, Chein and Schneider, 2005; Coulthard et al., 2008; Langer and Imber, 1979; Raaijmakers and Shiffrin, 1992; Schneider, 2009; Shiffrin and Schneider, 1977). Repetitive events tend to fade from consciousness unless they have special significance. That is, voluntary actions we are conscious with will become automatic with practice. As they do so, we tend to lose executive control over them. In other words, effortful tasks show a wider spread of brain activity; the brain takes more time to solve novel problems and switching from one task to another seems to require additional mental resources beyond those involved in routine and automatic actions. The level of activity in the cortex (at least) drops with practice and automaticity. It seems to indicate the recruitment of neuronal resources that are needed to work together to perform a task that is new or unpredictable. 


\section{Introduction to Primarily Learning-Related Concepts that Can Be Viewed from Neuroscience}

\subsection{Transfer}

The phenomenon known as the transfer is one of the ultimate goals of teaching and learning. It encompasses the ability to learn in one situation and then use that learning, possibly in a modified or generalised form, in other circumstances (Sousa, 2011). The transfer is the key process involved in problem-solving, creative thinking, and all other higher mental processes of inventions and artistic products. Transfer can be described as a two-part process - transfer during learning and transfer of learning. In the former, the effects the past learning have on the acquisition and processing of new learning are highlighted, while in the latter, the degree to which the learner becomes capable of applying new learning to future situations is presented. Further, the transfer can be categorised as positive and negative transfers; in the positive transfer, prior learning helps the learner with new learning, while prior learning interferes with the learners understanding of new learning in the negative transfer. We can see here a close relationship between the concepts of making sense and meaning and transfer; the more the learner makes sense and meaning the better the function of transfer that takes place.

One way educators achieve successful transfer is by introducing integrated thematic units. Factors that affect the transfer process include the context and degree of original learning and critical attributes of a concept taught (Hunter, 2004). About the first factor, it is important to understand that if something is worth teaching, it needs to be taught well, while the second factor highlights the need to emphasise on unique characteristics of the concepts learned. Further, it is understood that significant and efficient transfer only occurs if we teach to achieve it (Hunter, 2004; Mestre, 2002; Perkins and Saloman, 1988). The proper and frequent use of transfer significantly enhances the constructivist approach (Brooks \& Brooks, 1999) to learning, and vice versa.

\subsection{Rehearsal}

Rehearsal is a critical component of learning that helps the transfer of information from working memory to long-term storage. There are two major factors associated with the process of rehearsal - the amount of time devoted to rehearsal and the type of rehearsal (Sousa, 2011). The amount of time devoted to rehearsal can be found in two stages, either initial or secondary rehearsal. Initial rehearsal occurs when information first enters working memory (when sense and meaning are attached). Several studies showed that during longer rehearsals, which may even take place at a secondary stage, the amount of activity in the frontal lobe determined whether items were stored or forgotten (Buckner, Kelley \& Petersen, 1999; Wagner et al., 1998).

Another categorisation of the task of practising or rehearsal is whether it is massed practice or distributed practice. Practising new learning during time periods that are very close together is called massed practice; immediate memory is involved greatly here. Some example situations are mentally rehearsing a new phone number, cramming for an exam and trying a 
different example of applying new learning in a short period. In distributed practice, more sustained practice over time is done or introduce a spacing effect, which is the key to retention, as in the case of secondary rehearsal (Seabrook, Brown \& Solity, 2005; Metcalfe, Kornell \& Son, 2007; Carpenter, Pashler \& Cepeda, 2009; Hunter, 2004). A spiral curriculum in which key concepts are revised at regular intervals is a method we can use to engage learners in distributed practice.

The type of rehearsal can also be either rote or elaborative rehearsal. When the learner has to remember information exactly the way it entered the working memory, it is termed as rote rehearsal. Some examples are when a poem, telephone number, or multiplication table is remembered. Elaborative rehearsal takes place when new learning is associated with prior learning to form new connections. The assignment of sense and meaning to new learning can only occur if the learner has adequate time to process and reprocess (rehearsal) it. When learners get very little time for elaborative rehearsal, they have no option but to resort more frequently to rote rehearsal.

\subsection{Bloom's Taxonomy}

Blooms Taxonomy is one of the most popular models used for evaluating the level of learning for several years (Sousa, 2011). The original model of Bloom's Taxonomy (Bloom, Engelhart, Furst, Hill \& Krathwohl, 1956) had six complexity levels, namely, Knowledge, Comprehension, Application, Analysis, Synthesis, and Evaluation. It held that the six levels were cumulative - a lower level needs to be satisfied before moving to a higher level. A revised model was presented in 2001 (Anderson et al., 2001) retaining all the six levels. In the revised taxonomy, names of all levels were changed to verb form, three levels renamed and two were interchanged to a classification of Remember, Understand, Apply, Analyse, Evaluate and Create. In contrast to the original model, the strict hierarchy in the 2001 revision has been loosened to allow levels to overlap one another.

\subsection{Inductive and Deductive Reasoning in Bloom's Taxonomy}

Recent neuroscience studies have found different cerebral regions were involved in solving problems of logic and sequence (deductive reasoning) than in addressing open-ended problems with multiple answers (inductive reasoning) (Jausovec \& Jausovec, 2000; Mihov, Denzler \& Forster, 2010; Parsons \& Osherson, 2001). This evidence weakens Bloom's initial notion that one type of thinking is dependent on the prior activation of lower level thinking. Cognitive psychologists have observed that, more specifically, the thinking skills at the upper levels were a lot more fluid than Bloom's rigid hierarchy suggested.

\subsection{Convergent and Divergent Thinking in Bloom's Taxonomy}

Cognitive psychologists have generally divided thought into two categories: convergent, lower-order thinking and divergent, higher-order thinking. The lower three levels of Bloom's Taxonomy describe a convergent thinking process whereby the learner recalls and focuses what is known and comprehended to solve problems through the application. The upper three levels of the Taxonomy describe a divergent thinking process in which the learner come up with new insights and discoveries or relationships that were not part of the original 
information. Recent research studies show that elaborative rehearsal, involving higher-order thinking skills, engages the brain's frontal lobe. Further, they indicate that different parts of the brain are involved as more complex problem-solving tasks are handled (Cole, Bagic, Kass \& Schneider, 2010; Kelly, Hester, Foxe, Shpaner \& Garavan, 2006).

\subsection{The Constructivist Theory of Learning and Bloom's Taxonomy}

It is interesting to note that constructivist teachers, more specifically, ask open-ended questions and continually encourage students to analyse, evaluate and create (Brooks and Brooks, 1999). That is, it appears that teachers, who constantly use the upper levels of Bloom's revised taxonomy, are essentially demonstrating constructivist behaviours. However, we observe schooling still demands mostly the processing levels of convergent thinking. Common pedagogical practices and assessment focus on content acquisition through rote rehearsal, rather than on processes of analysis, synthesis and evaluation. Repeating the exact answers becomes more important than the processes used to get the answer.

\subsection{Bloom's Taxonomy and Complexity and Difficulty Levels}

About Bloom's Taxonomy, the terms complexity and difficulty are used to describe different mental operations. However, often we find them being used synonymously. In Boom's Taxonomy, we say, there are six levels of complexity. Complexity describes the thought process or a level of thought that the brain uses to deal with information. The difficulty, on the other hand, refers the amount of effort, and possibly time, the learner must expend, usually within a single level of complexity, while engaging in learning. It is worth realising that a particular learning activity can become increasingly difficult without becoming more complex.

\subsection{Application of Bloom's Taxonomy for Achieving Higher-Order Learning}

It has been observed that if teachers understand and follow the revised Bloom's Taxonomy correctly, all members of a learner cohort, irrespective of individual differences, can be sent through a process of higher-order learning. One way to make this practically possible is to review the curriculum and remove the topics of the least importance to gain the time needed for practising at higher levels. Another approach is to integrate the new concepts with previously taught material and connect them to appropriate concepts in the other curriculum areas; here we are essentially using the process of transfer more appropriately in the teaching-learning context.

\subsection{Types of Problem Solving/Decision Making}

Individuals need to become better decision makers and problem solvers through education. In schools or colleges, we are usually given a problem or question, and we must find or write the correct answer (Baars and Gage, 2010). Usually, only one right answer exists to these questions or problems. For example, balancing a chequebook and remembering the capital city of a country are similar tasks. By finding the correct solution, we engage in veridical decision-making. However, apart from high school exams, college tests and factual and computational trivia, most decisions we make in our everyday lives do not have intrinsically 
correct solutions. That is, the decisions we make are not always objective, rather they are, in most cases, subjective. What career path to make, what location to visit on vacation are some such example decisions we make in ambiguous situations. By making a decision or choice, we engage in adaptive decision-making. Further, our best neural system performance is not for the exact symbol sequences that conventional computers handle so well. Rather, our brains are exceptionally good at dealing with complex, ill-defined, and novel challenges, the kinds that people must deal with in the real world. That is, humans are exceptionally flexible in adapting to new conditions.

The choices we make are not inherent in the situations at hand. There is a complex interplay between the properties of the situations and our own individual properties, aspirations, doubts, and histories. The prefrontal cortex (PFC) is central to such decision-making or evaluation. Finding solutions for deterministic situations often is accomplished algorithmically or following several steps routinely. These tasks are increasingly delegated to various devices such as calculators, computers and the like. However, making judgments, in the absence of inherently correct solutions, remain, at least for now, a uniquely human territory. Thus, through education, an individual must develop the capacity to have the flexibility to adopt different perspectives on the same situation at different times. The organism must be able to disambiguate the same situation in multiple different ways and to have the capacity to switch between them at will. Frontal lobes of the brain hemispheres play a major role in dealing with these ambiguous situations.

\section{Assessing Learners Following Concepts in Educational Neuroscience}

\subsection{Assessing Abstract Concepts/Higher-Order Learning and How They Relate to Semantic/Episodic Memories}

We, as educators, have a general understanding that assessment should test what is referred to as higher-order learning or divergent thinking. The term higher-order learning relates well to higher end of the hierarchy of levels described in Blooms Taxonomy (Bloom, Engelhart, Furst, Hill \& Krathwohl, 1956; Anderson et al., 2001; Biggs, 2003; Entwistle, 1998), a popular tool among educators used for classifying the type or quality of learning. In Bloom's taxonomy, we have evaluation and creation at higher levels while comprehension and knowledge are at lower levels; analysis and application processes are found in the middle. When we refer to assessing higher-order learning, we essentially want to assess our learners for their ability to create and evaluate. In tasks of creation, learners formulate relatively novel answers on the fly by integrating pieces of knowledge he/she possesses about the question asked. This process contrasts from making learners merely recall what someone else said or the textbook presented as is; rather, it is a personalised and accurate view or judgement of the learner. In the evaluation, learners compare and contrast contents with/from other related memories, usually high-level concepts, he or she has retained. Again, this is a task done on the fly, instead of providing a highly practised or premeditated answer. Looking at this from another perspective, we want our learners to demonstrate their understanding of underlying abstract concepts. When abstract concepts are well grasped, they can be readily associated 
with many relevant areas or contexts. We reiterate that in Kolb's experiential learning cycle (Kolb, 1983), abstract conceptualisation is considered as the most important stage in learning (Watagodakumbura, 2016; Zull, 2002). It is the stage of a learning process in which learners spend time absorbing abstract concepts deeply, relating them to as many contexts as possible (Watagodakumbura, 2015a; 2015b). This premise of highlighting abstract concepts in both learning as well as assessment can now be validated by the evidence available in neuroscience. Our high-level knowledge or abstract concepts are stored in our brains as semantic memory, the type of memory that lasts longer. On the other hand, more specific or narrower details about certain situations are stored in episodic memory and are more susceptible to forgetting quickly (Baars \& Gage, 2010). Further, episodic memory is associated with sources of time and space while semantic memories are independent of sources of time and space. Now we see that high-level concepts are generalised summaries of knowledge or facts that are valid beyond the time and space of occurring. Thus, they are applicable in many broader contexts. Consequently, in assessments, it is justified that we test learners understanding of these abstract concepts associated with semantic memory ahead of more specific details associated with traces of episodic memory that are valid only within limited contexts of a particular time and space. Also, generalised concepts have the capacity to penetrate other domains of knowledge and application so that a deeper understanding of them has a more lasting value into the future, and worth investing an adequate time. In essence, we can say that learners are likely to achieve the transfer of learning, a prime objective of any educational environment so that they can utilise their learning in a more diverse set of situations.

\subsection{Assessment Taking Constructivism and Implicit Learning into Consideration}

The constructivist theory of learning (Brooks and Brooks, 1999; Biggs, 2003) indicates that during a teaching-learning process, every learner creates knowledge internally and independently. That is, every learner creates subjective knowledge based on his existing knowledge base. The term existing knowledge base refers to what the learner has retained in a lasting manner, and that retained information could also be spontaneously recalled when required. From the point of view of neuroscience, when new knowledge is created internally, learners create new neural networks and associate them with the existing neural networks. Associating newly created neural networks to existing neural networks is crucial regarding creating lasting memories or making sense of what is learned and accomplishing a function of transfer (Watagodakumbura, 2015c; 2015d). We clearly understand two important points here; that is knowledge is subjective (Yero, 2002) as opposed to being objective and that learning has a physical meaning, which indicates the growth of neurones to make more connected networks (Diamond, 1996, 2001; Zull, 2002). Knowledge is subjective because every individual carries different knowledge bases or neural networks which he or she can associate readily or spontaneously to newly learned knowledge. Consequently, the end results or final connected neural networks formed are different from one individual to the other. In effect, we as educators should discourage every single learner from providing identical answers, exactly in the form we presented to them. To achieve this objective, we can ask relatively novel and open-ended conceptual questions (Watagodakumbura, 2016). We deviate 
from asking questions that require regurgitation of factual and exact recalled information; that is, we keep away from questions that need an associative recall. Some possible simple examples of associative recall type questions are "What is the capital city of Australia?" or "Who is the President of China?" Such questions only require a rote rehearsal (see section 3.2) effort from learners. Further, answers to these questions can be instantaneously provided if learners have rote rehearsed them well and required little processing involving multiple brain regions, in constructing the answer. Also, if learners have access to modern technology in the form of the World Wide Web or Internet, finding answers to such questions can be a trivial task. Consequently, by making learners rote memorise answers to such questions, we as educators may be wasting valuable learner time for no purposeful gain regarding learning per se.

Further, evidence from neuroscience shows that the most of the learning we do as human beings is implicit (Baars \& Gage, 2010). In academic environments, we mostly have explicit learning in which the teacher tells learners what to learn and try to get brain resources focused on the particular task being learned. On the other hand, implicit learning takes place unconscious to the learner and does not have to take place in an academic or teaching-learning environment. Even in an academic environment, an individual learner can engage in implicit learning, by creating subjective, individualised knowledge, not usually intended by the facilitator or curriculum. Another related term we use is incidental learning (Eide \& Eide, 2004) in which human beings learn implicitly by observing an incident or undergoing a situation. Now, we see an interesting relationship between constructivism and implicit learning. Since learners make subjective knowledge internally and individually and most of our learning is implicit, in assessments, we as educators must accommodate learners to provide their subjective responses, followed by an evaluation of their validity (Watagodakumbura, 2015c; 2015d). That is, we must be mindful that even in a formal teaching-learning environment, learners can learn certain pieces of knowledge implicitly depending on their background and engagement level. Put differently, learners may create new knowledge that the teacher may not have implied or given out directly. Considering this situation, asking objective type questions where there is one correct answer will not encourage our learners to be creative and unique in providing their responses; it does not allow us to evaluate learners on the level of higher-order learning or divergent thinking achieved. Rather, it promotes a rote learning environment in which learners tend to commit facts to short-term memory, exactly as given by the teacher or textbook, in preparation for assessment tasks. In summary, we must set assessment in a manner that allows learners to respond subjectively as well as to demonstrate their implicit learning which should then be evaluated for the level of higher-order learning demonstrated. To engage in higher-order learning as described here, learners will essentially have to engage in elaborate rehearsal as opposed to rote rehearsal processes. Higher-order learning assessment questions are generally open-ended and contrast from the ones that prompt learners to merely reproduce specific facts memorised. 
4.3 Appropriately Assessing Gifted Learners Who Learn Implicitly and Incidentally More Elaborately

Learners who are identified as gifted were observed to use right cerebral hemispheric functions more predominantly as visual-spatial learners (Silverman, 1998, 2002). It is one reason that they are found to be at the receiving end when encountered with traditionally left cerebral hemisphere biased educational systems with predominant auditory-sequential instructions. It is also worth noticing that gifted learners are highly capable in incidental or implicit learning (Eide \& Eide, 2004), and they will be disadvantaged, as that happens in traditional classrooms, if assessments are set in the manner mentioned in the previous section, encouraging and giving the opportunity for them to provide their subjective and creative responses utilising the right hemisphere. In addition, providing a better learning environment for gifted individuals, who demonstrate a higher level of overexcitable characteristics (Dabrowski, 1970, 1972, 1977), we can be more inclusive (Goleman, 2005; Webb, 2005, 2008) in our pedagogical practices, within a neurodiverse (Armstrong, 2011; Watagodakumbura, 2016) society.

\subsection{Assessment Encouraging Adaptive Decision Making Ahead of Veridical Decision Making}

We have seen that learners construct subjective meaning from what they learn. Also, most of the learning is implicit or unconscious to the learner and sometimes may not have been implied by the teacher. Further, we have recognised that higher-order learning or high-level concepts learned last longer in learners' memories, are more useful in general and are not valid restrictively for sources of limited time and space. In the presence of this evidence, the challenge now is to identify ways to construct assessments appropriately yielding validity. That is, assessments need to focus on testing higher-order learning or the ability to create and evaluate, which is essentially retained in long-term memory. We should note that human brains are selectionist, unlike conventional computers which are instructionists (Baars \& Gage, 2010). That is, computers are relying on a limited set of symbols to identify a predefined solution while human brains can produce new solutions altogether by forming new neural networks that did not exist before. That is why human beings are identified be creative while typical computers are not (Beale \& Jackson, 1990). The term higher-order learning is used to highlight that we create new connections among neural networks to create new knowledge when we learn. In other words, human brains are better or naturally inclined in adaptive decision making while computers are better in veridical decision making; that is, human brains can adapt to new situations in an entirely novel manner while computers can only find an existing or predefined solution (Watagodakumbura, 2015a; 2015b). In adaptive decision making, you usually take many inputs into consideration and come to an optimised solution rather than a hundred percent correct solution.

\subsection{Assessment Encouraging Recognition Tests Ahead of Associative Recall}

In contrast to adaptive decision making, veridical decision making generally takes into consideration a relatively lower number of inputs we come to a hundred percent correct answer. We can see here that when we take a lower number inputs into account, coming to a specific or definite conclusion is not difficult. Answers human brains are better in producing 
will not have a single right answer; rather the answer will be dependent on the way learners have argued or evaluated to make a valid judgment on a somewhat ambiguous situation. In most of our life situations, we make adaptive decisions in the presence of ambiguous conditions. More importantly, we as individuals will adapt to a given situation in different ways due to our individual differences; some will take a lower number of inputs or dimensions into consideration while the others will take a higher number into account. Further, the same individual may take a different number of inputs or dimensions into consideration in various stages of his or her life, resulting in different adaptive decisions at different times. It is different from applying a routine algorithm on a relatively limited number of inputs to come to the same answer again and again, as typical computers do. Now we have some clues on how we should direct our assessments so that learners are better guided to engage in their learning as well as to improve the validity of assessment in a lasting manner. We should give learners the opportunity to provide creative and individualised responses and then evaluate them for the level of quality and degree of validity. In other words, we should design and ask open-ended questions that require subjective or more optimised answers instead of objective type questions that yield one correct answer from our learners. Further, these open-ended questions inherently are based on testing the understanding of abstract concepts rather than specific details; this is because specific details generally yield from a veridical decision-making process (Watagodakumbura, 2015a; 2015b). We are essentially avoiding here associative recall type questions and incline towards recognition tests. In the former type, reproduction of exactly memorised facts is done while in the latter, awareness or understanding of a high-level concept is demonstrated in the presence of some clues or priming content. Recognition tests are more common in our lives as we should have the ability to recall previously learned concepts readily when the circumstances require if we have done learning effectively. On the other hand, an associative recall task may only be effective for a limited time following a rote rehearsal activity.

4.6 Considering the Time Factor of Assessments When Individualised, Unique Answers are Expected Essentially Utilising Frontal Lobes

We now understand that most of the decisions we make in day-to-day life situations are adaptive in nature. To improve the quality of our adaptive decisions or to take the most optimal decision, we should take as many dimensions of the problem at hand as possible into consideration. There are no strict procedures or predefined routine actions to carry out until one specific answer is obtained, as in the case of veridical decision making. In adaptive decision making, in the presence of ambiguous conditions, the frontal cortex of our brain gets involved extensively, resulting in more executive control (Baars \& Gage, 2010). Considering that the frontal lobes played a significant role in the evolution of human civilisation, making use of our frontal lobes in our regular decision making is indeed a positive sign; that is, we take advantage of highly evolved physiological resources and human characteristics for optimal decision making. It is interesting to note that when frontal cortex gets involved in decision making, it takes relatively longer time for the process. The reason for this longer time could be because the role played by frontal lobes as an organ connecting most of the other parts of the brain. Thus, they integrate information received from many other parts of the brain, understandably a slower process. In timed tests/assessments, since we have a 
limited time to evaluate learners, it is important that we create questions at higher complexity levels but not at higher difficulty levels. Questions at higher difficulty levels may utilise more time and effort from learners' point of view, but not necessarily testing higher-order thinking abilities or transfer of learning (Watagodakumbura, 2015c; 2015d). Further, since we have only a limited time to conduct timed tests/assessments, they become statistical analyses that allow only a sample set of questions rather than all possible questions. That is, we should take special care not to overload the examination paper with too many questions, not allowing learners adequate time to formulate and write down answers.

\subsection{Discouraging Learners Succumbing to Automaticity in Producing Habitual Answers}

When we get involved in routine activities for a longer period, such as in the case of habituation, the phenomenon known as automaticity results; when this happens, voluntary actions become automatic and less cortical resources are used for the underlying process. Consequently, the time required to complete a routine task that has been practised to a level of automaticity becomes relatively less. Now we can apply this timing concept to formulate our assessments better. First, we want to conclude that we need our learners to engage in an adaptive decision making or optimising process on the fly, thus deviating from providing a premeditated or habitual answer. Further, we need to set our assessments in a manner that learners must provide individualised or unique answers after making evaluations and judgement on a somewhat ambiguous situation during the process. To achieve this task, learners should connect as many related neural networks as possible to get the most optimal decision. This process essentially utilises the frontal cortex and understandably requires relatively longer time. We should not set our assessments in a manner that learners are only required to regurgitate premeditated or practised answers quickly; instead, learners should be required to provide novel answers to reasonably novel questions we set. When answers are provided to novel questions, cortical resources are utilised better and avoids the phenomenon of automaticity (Baars \& Gage, 2010). Considering this situation, we as educators have the responsibility to provide an adequate time for learners, to construct their subjective answers to open-ended questions we set and to write them back on the paper; a sound judgement from us, the educators, is essential on this assessment timing matter (Watagodakumbura, 2016).

\subsection{Assessments that Help Enhancing Learner Consciousness and Wisdom}

We as educators have understood the need for us to set assessments to test understanding of abstract concepts. Since abstract concepts are summaries of generalised knowledge, they have the power of penetrating into many domain areas and applications of knowledge or neural networks. That is, a single abstract concept has the propensity to be utilised in several applications across multiple domains. Since our brain consists of many differentiated functional areas, it is highly likely that knowledge about different domains is stored in different regions of the brain. Consequently, when we focus on evaluating the understanding of abstract concepts in assessment, we encourage learners to use multiple brain regions or functional areas to provide responses; that is, they are encouraged to use a larger number of neural networks across the brain. When this happens, learners are directed to use their frontal cortex more elaborately, as it is the part of the brain that connects most of the other 
regions. Further, when we set our assessments in a manner that learners should answer open-ended and novel questions with somewhat ambiguous conditions, the frontal cortex gets involved essentially. As presented by neuroscientists, consciousness is the phenomenon that multiple differentiated brain areas and functions are integrated, and evolution of consciousness is considered as the highest expression of human development (Baars \& Gage, 2010). Consequently, when we focus on open-ended questions targeting abstract concepts, we are directing our learners on a path to enhance consciousness, a prime human quality, as understood by scientists; that is, we are guiding our learners to become the best they can be as human beings. Similarly, when we integrate knowledge of multiple domains areas, and possibly functional areas, to make useful inferences, we develop what educationists refer to as wisdom (Claxton, 2008). Wisdom, in fact, is a higher form of creativity that utilises knowledge of multiple domain areas. The frontal lobe, which is recognised as the organ of civilisation and integrates many brain areas together, plays a significant role in the tasks of enhancing consciousness and wisdom. That is, we should direct our learners to use frontal cortex as much as possible through our assessment activities. Thus, when we as educators set our assessments focusing understanding of abstract concepts and ask open-ended questions for learners to thrive, we are directing our learners to enhance consciousness and develop wisdom, higher human features achievable in the process of human evolution (Watagodakumbura, 2015a; 2015b). That is, we put learners on a path to a higher level of human development or self-actualisation ((Maslow, 1968, 1993; Dabrowski, 1970, 1977) so that they could see the reality better, like having many open eyes, and become better or more optimal problem solvers. In other words, when assessments focus on enhancing consciousness and wisdom towards higher levels of human development, learners essentially achieve the transfer of learning, a prime objective of any educational environment, so that they can freely or more spontaneously make use of their retained knowledge.

\section{Conclusion}

Taking the critical dimension of educational neuroscience into consideration, we have presented many, not only important but, essential practices educators must use to improve the quality of learner assessment by addressing the subtle but important factors such as validity, fairness and lasting outcomes. We highlighted the need to use open-ended conceptual questions that give learners the freedom to creatively express their individualised answers or solutions. As these answers are provided to relatively novel questions on the fly, essentially using lasting semantic memories, learners do not succumb to the phenomenon of automaticity in which they provide highly practised habitual answers. By discouraging learners from providing habitual answers, we distant them from rote rehearsal exercise as part of engaging in learning. As we encourage learners to create idiosyncratic or adaptive answers (as opposed to making veridical decisions) to open-ended questions with an acceptable level of accuracy (but not essentially with immaculate precision), we direct learners on a path to higher-order learning involving inductive and divergent thinking processes. Thus, learners develop neural networks of knowledge, essentially crossing disciplinary boundaries, resulting in higher levels of human development with enhanced wisdom and consciousness. Wisdom or 
consciousness of learners is enhanced when they identify new connections among their existing knowledge networks and the new knowledge introduced, irrespective of disciplinary boundaries. This process of integrating neural networks of knowledge essentially make use of the frontal lobes, the organ of civilisation. Further, as such an integration process takes relatively longer time than providing automatic or habitual responses, we as educators need to give particular emphasis on deciding the time factor of assessment. Designing and constructing assessments, though trivial it may appear, can be the catalyst for learners to engage in deep learning towards higher levels of human development, which is well supported by our brain and neural structures.

\section{References}

Anderson, L. W. (Ed.), Krathwhol, D. R. (Ed.), Airasian, P. W., Cruikshank, K. A., Mayer, R. E., Pintrich, P. R., Raths, J. \& Wittrock, M. C. (2001). A taxonomy for learning, teaching and assessing: A revision of Bloom's Taxonomy of Educational Objectives (Complete edition). New York: Longman.

Armstrong, T. (2011). The Power of Neurodiversity: Unleashing the Advantages of Your Differently Wired Brain. Da Capo Lifelong Books.

Baars, B. J., \& Gage, N. M. (2010). Cognition, Brain, and Consciousness - Introduction to Cognitive Neuroscience( $2^{\text {nd }}$ Ed.). Elsevier, MA: USA.

Baars, B. J., Banks, W. P., \& Newman, J. B. (2003). Essential sources in the scientific study of consciousness. Cambridge: MIT Press.

Baddeley, A. D. (2000). The episodic buffer: a new component of working memory? Trends in Cognitive Sciences, 4(11), 417-423. http://dx.doi.org/10.1016/S1364-6613(00)01538-2

Baddeley, A. D., \& Hitch, G. J. (1974). Working memory. In G. A. Bower (Ed.), Recent advances in learning and motivation: 8 (pp. 47-90). New York: Academic Press. http://dx.doi.org/10.1016/s0079-7421(08)60452-1

Balduzzi, D., \& Tononi, G. (2008). Integrated Information in Discrete Dynamical Systems: Motivation and Theoretical Framework. PLoS Computational Biology, 4(6). http://dx.doi.org/10.1371/journal.pcbi.1000091

Banaji, M. R., \& Greenwald, A. G. (1995). Implicit gender stereo-typing in judgements of fame. Journal of Personality and Social Psychology, 68(2), 181-198. http://dx.doi.org/10.1037/0022-3514.68.2.181

Beale, R., \& T. Jackson. (1990). Neural Computing - An Introduction. Institute of Physics Publishing. http://dx.doi.org/10.1887/0852742622

Berry, D. C., \& Dienes, Z, (1993). Implicit learning: Theoretical and empirical issues. Erlbaum.

Biggs, J. (2003). Teaching for Quality Learning at University (2 ${ }^{\text {nd }}$ ed.). Buckingham, Society 
for Research into Higher Education and Open University Press.

Bloom, B. S. (Ed.), Engelhart, M. D., Furst, E. J., Hill, W. H., \& Krathwohl, D. R. (1956). Taxonomy of educational objectives: The classification of educational goals. Handbook 1: Cognitive domain. New York: David McKay.

Bowers, K. S., Regehr, G., Balthazard, C., \& Parker, K. (1990). Intuition in the context of $\begin{array}{llll}\text { discovery. } & \text { Cognitive } & \text { Psychology, } & \text { 22(1), }\end{array}$ http://dx.doi.org/10.1016/0010-0285(90)90004-N

Brooks, J. G., \& Brooks, M. G. (1999). In search of understanding: The case for constructivist classrooms ( $2^{\text {nd }}$ ed.) Alexandria, VA: Association for Supervision and Curriculum Development.

Buckner, R. L., Kelley, W. M., \& Petersen, S. E. (1999). Frontal cortex contribution to human memory formation. Nature Neuroscience, 2, 311-314. http://dx.doi.org/10.1038/7221

Carpenter, S. K., Pashler, H., \& Cepeda, N, J. (2009). Using tests to enhance $8^{\text {th }}$ grade students' retention of U.S. history facts. Applied Cognitive Psychology, 23, 760-771. http://dx.doi.org/10.1002/acp.1507

Chein, J. M., \& Schneider, W. (2005). Neuroimaging studies of practice-related change: fMRI and meta-analytic evidence of a domain-general control network for learning. Brain Research. Cognitive Brain Research, 25(3), 607-623. http://dx.doi.org/10.1016/j.cogbrainres.2005.08.013

Claxton, G. (2008). Wisdom: Advanced Creativity? In A. Craft, H. Gardner \& G. Claxton (Eds.), Creativity, Wisdom and Trusteeship: Exploring the Role of Education. Thousand Oaks, CA: Corwin Press.

Cleeremans, A. (1993). Mechanisms of implicit learning: Connectionist models of sequence learning. MIT Press.

Cohen, N. J., \& Squire, L. R. (1980). Preserved learning and retention of pattern-analysing skill in amnesia: Dissociation of knowing how and knowing that. Science, 210(4466), 207-210. http://dx.doi.org/10.1126/science.7414331

Cole, M. W., Bagic, A., Kass, R., \& Schneider, W. (2010). Prefrontal dynamics underlying rapid instructed task learning reverse with practice. The Journal of Neuroscience, 30(42), 14245-14254. http://dx.doi.org/10.1523/JNEUROSCI.1662-10.2010

Coulthard, E. J,. Nachev, P., \& Husain, M (2008). Control over conflict during movement preparation: Role of posterior parietal cortex. Neuron, 58(1), 144-157. http://dx.doi.org/10.1016/j.neuron.2008.02.009

Cowan, N., Izawa, C., \& Ohta, N. (2005). Working-memory capacity limits in a theoretical context. Human learning and memory: Advances in theory and application. The $4^{\text {th }}$ Tsukuba International Conference on Memory. Mahwah: Lawrence Erlbaum Associates, Publishers, p. 155. http://dx.doi.org/10.4324/9780203342398 
Curran, T. (2001). Implicit learning revealed by the method of opposition. Trends in Cognitive Sciences, 5(12), 503-504. http://dx.doi.org/10.1016/S1364-6613(00)01791-5

Dabrowski, K. (1972). Psychoneuroses Is Not An Illness. London: Gryf Publications.

Dabrowski, K. (1977). Theory of Levels of Emotional Development (vol 1) - Multilevelness and Positive Disintegration. New York: Dabor Science Publications.

Dabrowski, K. (with Kawczak A. and Piechowski M. M.). (1970). Mental Growth through Positive Disintegration. London: Gryf Publications

Diamond, M. C. (1996). The Brain...Use it or Lose It. New Horizons for Learning: School of Education, Johns Hopkins University. http://education.jhu.edu/newhorizons/Neurosciences/articles/.

Diamond, M. C. (2001). Response of the Brain to Enrichment. New Horizons for Learning: School of Education, Johns Hopkins University. http://education.jhu.edu/newhorizons/Neurosciences/articles/.

Dudai, Y. (2004). The neurobiology of consolidations, or how stable is the engram? Annual Review of Psychology, 51 http://dx.doi.org/10.1146/annurev.psych.55.090902.142050

Edelman, G. M. (1989). The remembered present: A biological theory of consciousness. New York: Basic Books Inc.

Edelman, G. M. (1993). Neural Darwinism: Selection and re-entrant signalling in higher brain function. Neuron, 10(2), 115-125. http://dx.doi.org/10.1016/0896-6273(93)90304-A

Edelman, G. M. (2005). Wider than the Sky: The Phenomenal Gift of Consciousness. Yale University Press, New Haven.

Edelman, G. M. (2007). Second Nature: Brain Science and Human Knowledge. Yale University Press, New Haven.

Edelman, G. M., \& Mountcastle, V. B. (1978). The mindful brain: Cortical organisation and the group-selective theory of higher brain function. Oxford: MIT Press.

Edelman, G. M., \& Tononi, G. (2001). A universe of consciousness: How matter becomes imagination. New York: Basic Books Inc.

Eide, B., \& Eide, F. (2004). 'Brains on Fire: The Multimodality of Gifted Thinkers', New Horizons for Learning: School of Education, Johns Hopkins University. Retrieved from http://education.jhu.edu/PD/newhorizons/Neurosciences/articles/

Entwistle, N. J. (1998). Approaches to Learning and Forms of Understanding. In B. Dart and G. Boulton-Lewis, (ed.), Teaching and Learning in Higher Education, 72-101. Melbourne, Australia: Australian Council for Educational Research.

Fuster, J. M. (1997). Network memory. Trends in Neurosciences, 20(10), 451-459. http://dx.doi.org/10.1016/S0166-2236(97)01128-4 
Gazzaniga, M. S. (1998a). The mind's past. Berkeley: University of California Press.

Gazzaniga, M. S. (1998b). The split brain revisited. Scientific American, 279, 48-55. http://dx.doi.org/10.1038/scientificamerican0798-50

Gazzaniga, M. S., Ivry, R. B., \& Mangun, G. R. (2002). Cognitive neuroscience: The biology of the mind( $2^{\text {nd }}$ ed. $)$. New York: Norton.

Geschwind, N. (1979). Specialisations of the human brain. Scientific American, 241(3), 180-199. http://dx.doi.org/10.1038/scientificamerican0979-180

Goldberg, E. (2001). The executive brain: Frontal lobes and the civilised mind (Vol xix). New York: Oxford University Press.

Goleman, D. (2005). Emotional Intelligence. New York: Bantam Books.

Hobson, J. A., \& Stickgold, R. (1995). Sleep. Sleep the beloved teacher? Current Biology, 5(1), 35-36. http://dx.doi.org/10.1016/S0960-9822(95)00011-X

Hunter, M. (2004). Mastery Teaching. Thousand Oaks, CA: Corwin.

Ingvar, D. H. (1985). Memory of the future: An essay on the temporal organisation of conscious awareness. Human Neurobiology, 4(3), 127-136.

James, W. (1890). The principles of psychology (Vol. I). New York: Henry Holt and Co, Inc. http://dx.doi.org/10.1037/11059-000

Jausovec, N., \& Jausovec, K. (2000). EEG activity during the performance of complex mental problems. International Journal of Psychophysiology, 36, 73-88. http://dx.doi.org/10.1016/S0167-8760(99)00113-0

Kelly, A. M. C., Hester, R., Foxe, J. J., Shpaner, M., \& Garavan, H. (2006). Flexible cognitive control: Effects of individual differences and brief practice on a complex cognitive task. Neuroimage 31, 866-886. http://dx.doi.org/10.1016/j.neuroimage.2006.01.008

Knowlton, B. J., Mangels, J. A., \& Squire, L. R. (1996). A neostriatal habit learning system in humans. $\quad$ Science, 273(5280), 1399-1402. http://dx.doi.org/10.1126/science.273.5280.1399

Koch, C. (1996). A neural correlates of consciousness? Current Biology, 6(5), 492. http://dx.doi.org/10.1016/S0960-9822(02)00519-5

Koch, C., \& Tononi, G. (2008). Can Machines be Conscious? IEEE Spectrum, 45(6), 55-59. http://dx.doi.org/10.1109/MSPEC.2008.4531463

Kolb, D. (1983). Experiential Learning: Experience as the Source of Learning and Development, Upper Saddle River, NJ: Prentice Hall.

Langer, E. J., \& Imber, L. G. (1979). When practice makes imperfect: Debilitating effects of overlearning. Journal of Personality and Social Psychology, 37(11), 2014-2024. http://dx.doi.org/10.1037/0022-3514.37.11.2014 
LeDoux, J. E. (1996). The emotional brain. New York: Simon \&Schuster.

Lees, G. V., Jones, E. G., \& Kandel, E. R. (2000). Expressive genes record memories. Neurobiology of Disease, 7(5), 533-536. http://dx.doi.org/10.1006/nbdi.2000.0348

Luria, A. R. (1966). Higher cortical functions in man (translated by Haigh). London: Tavistock.

Luria, A. R. (1976). The neuropsychology of memory (translated by Haigh). Oxford: V. H. Winston \& Sons.

MacLean, P. D. (1967). The brain in relation to empathy and medical education. The Journal of Nervous and Mental Disease, 144(5), 374-382. http://dx.doi.org/10.1097/00005053-196705000-00005

Maslow, A. (1968). Toward a Psychology of Being. New York: Van Nostrand Reinhold.

Maslow, A. (1993). Farther Reaches of Human Nature. New York, N.Y., U.S.A.: Arkana.

McGaugh, J. L. (2000). Memory - A century of consolidation. Science, 287(5451), 248-251. http://dx.doi.org/10.1126/science.287.5451.248

Mestre, J. (2002). Transfer of learning: Issues and research agenda. Arlington, VA: National Science Foundation.

Metcalfe, J. (1986). Feeling of knowing in memory and problem solving. Journal of Experimental Psychology. Learning, Memory, and Cognition, 12(2), 288-294. http://dx.doi.org/10.1037/0278-7393.12.2.288

Metcalfe, J., Kornell, N., \& Son, L. K. (2007). A cognitive-science based programme to study efficacy in a high and low-risk setting. European Journal of Cognitive Psychology, 19, 743-768. http://dx.doi.org/10.1080/09541440701326063

Mihov, K. M., Denzler, M., \& Forster, J. (2010). Hemispheric specialisation and creative thinking: A meta analytic review of lateralisation of creativity. Brain and Cognition, 72(3), 442-448. http://dx.doi.org/10.1016/j.bandc.2009.12.007

Nauta, W. J. (1972). Neural association of the frontal cortex. Acta Neurobiologiae Experimentalis (Wars), 32(2), 125-140.

Palmer, S. E. (1999). Colour, consciousness, and isomorphism constraint. Discussion 944-989. The Behavioural and Brain Sciences, 22(6), 923-943. http://dx.doi.org/10.1017/S0140525X99002216

Panksepp, J. (1998). Affective neuroscience: The foundations of human and animal emotions. New York: Oxford University Press.

Parsons, L. M., \& Osherson, D. (2001). New evidence for distinct right and left brain systems for deductive versus probabilistic reasoning. Cerebral Cortex, 11, 954-965. http://dx.doi.org/10.1093/cercor/11.10.954 
Penfield, W., \& Milner, B. (1958). Memory deficit produced by bilateral lesions in the hippocampal zone. AMA Archives of Neurology and Psychiatry, 79(5), 475-497. http://dx.doi.org/10.1001/archneurpsyc.1958.02340050003001

Perkins, D., \& Salomon, G. (1988). Teaching for Transfer. Educational Leadership, 46, 22-32.

Phelps, E. A., \& LeDoux, J. E. (2005). Contributions of the amygdale to emotion processing: From animal models to human behaviour. Neuron, 48(2), 175-187. http://dx.doi.org/10.1016/j.neuron.2005.09.025

Raaijmakers, J. G., \& Shiffrin, R. M., (1992). Models for recall and recognition. Annual $\begin{array}{llll}\text { Review of } & \text { Psychology, 205-234. }\end{array}$ http://dx.doi.org/10.1146/annurev.ps.43.020192.001225

Ryle, G. (1949). The concept of mind. London: Hutchinson.

Schneider, W. (2009). Automaticity and consciousness. Elsevier Encyclopaedia of Consciousness. In W. Banks (Ed.), Encyclopaedia of Consciousness ( $\left.1^{\text {st }} \mathrm{ed}\right)(\mathrm{pp} .83-92)$. Amsterdam: Academic Press. http://dx.doi.org/10.1016/B978-012373873-8.00009-8

Seabrook, R., Brown, G. D. A., \& Solity, J. E. (2005). Distributed and massed practice: From laboratory to classroom. Applied Cognitive Psychology, 19, 107-122. http://dx.doi.org/10.1002/acp.1066

Seitz, A., \& Watanabe, T. (2005). A unified model for perceptual learning. Trends in Cognitive Science, 9(7), 329-334. http://dx.doi.org/10.1016/j.tics.2005.05.010

Semenza, C., Delazer, M., Bertella, L., Grana, A., Mori, I., Conti, F. M., ...Mauro, A. (2006). Is math lateralised on the same side as language? Right hemisphere aphasia and mathematical abilities. Neuroscience Letters, 406, 285-288. http://dx.doi.org/10.1016/j.neulet.2006.07.063

Shiffrin, R. M., \& Schneider, W. (1977). Controlled and automatic human information processing: II. Perceptual learning, automatic attending and a general theory. Psychological Review, 84(2), 127. http://dx.doi.org/10.1037/0033-295X.84.2.127

Silverman, L. K. (2002). Upside-Down Brilliance: The Visual-Spatial Learner. Denver: DeLeon Publishing.

Silverman, L.K. (1998). Personality and Learning Styles of Gifted Children. In Excellence Educating Gifted \& Talented Learners ( $3^{\text {rd }}$ ed.), Van Tassel - Baska, Denver, Colorado, USA: Love Publishing Company.

Sousa, D. A. (2011). How the Brain Learns ( $4^{\text {th }}$ Ed.). Thousand Oaks, CA: Corwin.

Sperry, R. (1966). Brain bisection and consciousness. In J. Eccles (Ed.), How the self controls its brain. New York: Springer-Verlag.

Squire, L. R. (2004). Memory systems of the brain: A brief history and current perspective. 
Neurobiology of Learning and Memory, 82, 171-177. http://dx.doi.org/10.1016/j.nlm.2004.06.005

Squire, L. R. (2009). Memory and brain systems: 1969-2009. Journal of Neuroscience, 29(41), 12711-12716. http://dx.doi.org/10.1523/JNEUROSCI.3575-09.2009

Sweeney, M. S. (2009). Brain: The complete mind. Washington, DC: National Geographic.

Sylwester, R. (1998). The Downshifting Dilemma: A Commentary and Proposal. New Horizons for Learning: School of Education, Johns Hopkins University. Retrieved from http://education.jhu.edu/newhorizons/Neurosciences/articles/

Tononi, G. (2008). Consciousness as Integrated Information: A Provisional Manifesto. Biological Bulletin, 215(3), 216-242. http://dx.doi.org/10.2307/25470707

Tononi, G., \& Edelman, G. M. (1998)Consciousness and complexity. Science, 282(5395), 1846-1851. http://dx.doi.org/10.1126/science.282.5395.1846

Tulving, E. (1972). Episodic and semantic memory. In E. Tulving, W. Donaldson \& G. H. Bower (Eds.), Organisation of memory (pp. 381-403). New York: Academic Press.

Tulving, E. (1985). Elements of Episodic Memory. New York: Oxford University Press.

Tulving, E. (2002). Episodic memory: From mind to brain. Annual Review of Psychology, 53, 1-25. http://dx.doi.org/10.1146/annurev.psych.53.100901.135114

Wagner, A. D., Schacter, D. L., Rotte, M., Koutstaal, W., Maril, A., Dale, A. M., ...Buckner, R. L. (1998). Building memories: Remembering and forgetting of verbal experiences as predicted by brain activity. Science, 281, 1188-1191. http://dx.doi.org/10.1126/science.281.5380.1188

Watagodakumbura, C. (2015a). Identifying Sound Pedagogical Practices Based on Findings from Neuroscience. International Journal of Education, 7(2), 146-159. https://doi.org/10.5296/ije.v7i2.7318

Watagodakumbura, C. (2015b). Reflecting on Learner Assessments and their Validity in the Presence of Emerging Evidence from Neuroscience. in the journal of Higher Education Studies, 5(3), 58-65. http://dx.doi.org/10.5539/hes.v5n3p58

Watagodakumbura, C. (2015c) 'Reviewing the Purpose of Education and Challenges Faced in Implementing Sound Pedagogical Practices in the Presence of Emerging Evidence from Neuroscience', in World Journal of Education, 5(6), 23-36. https://doi.org/10.5430/wje.v5n6p23

Watagodakumbura, C. (2015d). Some Useful Pedagogical Practices: Educational Neuroscience Perspective. Journal of Studies in Education, 5(4), 191-221. https://doi.org/10.5296/jse.v5i4.8521

Watagodakumbura, C. (2016). Education from a Deeper and Multidisciplinary Perspective To a Sustainable Development of a Neurodiverse Society - A Futuristic View. USA: Book 
Venture.

Webb, J. T. (2008). Dabrowski's Theory and Existential Depression in Gifted Children and Adults. Paper presented at the Eighth International Congress of the Institute for Positive Disintegration in Human Development, August 7-9, Alberta, Canada.

Webb, J.T. (with Amend E. R., Webb N.E., Goerss J., Beljan P, and Olenchak F.R.) (2005). Misdiagnosis and Dual Diagnoses of Gifted Children and Adults: ADHD, Bipolar, Ocd, Asperger's, Depression, and Other Disorders. USA: Great Potential Press.

Yero, J. (2002). How Teacher Thinking Shapes Education. New Horizons for Learning: School of Education, Johns Hopkins University. Retrieved from http://education.jhu.edu/PD/newhorizons/Neurosciences/articles/

Yzerbyt, V. Y., Lories, G., \& Dardenne, B. (Eds.), (1998). Metacognition: Cognitive and social dimensions. Thousand Oaks: Sage Publications. http://dx.doi.org/10.4135/9781446279212

Zull, J. E. (2002). The Art of Changing the Brain: Enriching the Practice of Teaching by Exploring the Biology of Learning. Virginia, USA: Stylus Publishing.

\section{Copyright Disclaimer}

Copyright for this article is retained by the author(s), with first publication rights granted to the journal.

This is an open-access article distributed under the terms and conditions of the Creative Commons Attribution license (http://creativecommons.org/licenses/by/3.0/). 